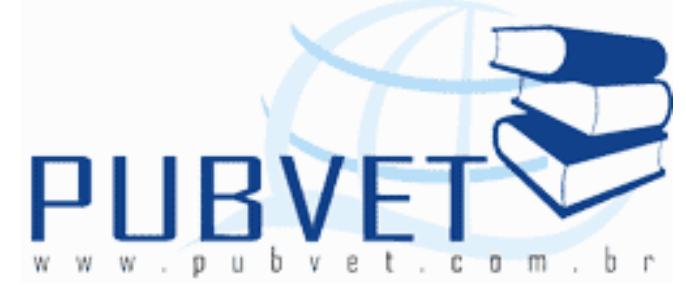

PUBVET, Publicações em Medicina Veterinária e Zootecnia.

\title{
Técnicas de superovulação em ruminantes
}

Vicente de Paula Fernandes Neto ${ }^{1}$, Marinna Nérica do Nascimento e Silva ${ }^{2}$, Flávio de Sousa Oliveira², José Ribamar Silva do Nascimento Júnior ${ }^{3}$

${ }^{1}$ Méd. Vet., Mestrando em Ciência Animal, Universidade Federal do Piauí. Autor para contato: vtefernandes@hotmail.com

${ }^{2}$ Méd. Vet., Doutorandos em Ciência Animal, Universidade Federal do Piauí

${ }^{3}$ Zootecnista, Universidade Federal do Maranhão

\section{Resumo}

O sucesso dos programas de transferência de embriões depende, em grande parte, da resposta à superovulação, seu fator limitante. Quanto a isso, recentes protocolos, que controlam a função folicular e luteínica, permitem iniciar o tratamento superovulatório em momento pré-determinado. 0 tratamento superovulatório objetiva suprir a deficiência da concentração de FSH antes que o folículo dominante promova a redução da concentração endógena dessa gonadotrofina. São inúmeros os protocolos para sincronização do estro e superovulação em ruminantes, com a utilização de vários fármacos como FSH, eCG, progestágenos, estrógenos, PGF2a, agonistas de GnRH, etc. São variados também os fatores que interferem no sucesso da superovulação em ruminantes dentre os quais destacam-se a regressão lútea precoce, relação $\mathrm{LH} / \mathrm{FSH}$, tipo de fármaco utilizado, imunidade, escore corporal e nutrição. 
FERNANDES NETO, V.P. et al. Técnicas de superovulação em ruminantes. PUBVET, Londrina, V. 6, N. 12, Ed. 199, Art. 1332, 2012.

Nesta revisão objetiva-se expor tais protocolos superovulatórios e o uso dos fármacos, assim como os efeitos dos fatores interferentes.

Palavras-chave: Ruminantes. Superovulação. Fármacos.

\title{
Techniques of superovulation in ruminants
}

\begin{abstract}
The success of transfer programs embryos depends in large part to superovulate response, its limitation. In this regard, recent protocols, which control the follicular and luteal function, allow you to start the superovulatory treatment in a predetermined time. The superovulated objective supply the deficiency of the concentration of FSH before the dominant follicle promote the reduction of the concentration of this endogenous gonadotropin. There are numerous protocols for estrus synchronization and superovulation in ruminants, with the use of various drugs such as FSH, eCG, progestin, estrogen, PGF2a, GnRH agonists, etc.. They are also the various factors affecting the success of superovulation in ruminants among which is the early luteal regression, LH / FSH ratio, type of drug used, immunity, nutrition and body condition. This review aims to expose these protocols and the use of superovulatory drugs, as well as the effects of interfering factors.
\end{abstract}

Keywords: Ruminants. Superovulation. Drugs.

\section{INTRODUÇÃO}

As fêmeas ruminantes domésticas são poliéstricas, apresentando estro em intervalos regulares de 21 dias na vaca e cabra e 17 dias na ovelha. Durante o ciclo estral ocorre uma cadeia de eventos que se repetem até o impedimento da luteólise pela gestação (nas ovelhas e cabras também por ocasião do anestro estacional). O processo de foliculogênese tem início com a formação dos folículos durante a vida fetal, ou seja, ao nascimento já possuem determinado o número de folículos primordiais nas suas gônadas. A maioria 
FERNANDES NETO, V.P. et al. Técnicas de superovulação em ruminantes. PUBVET, Londrina, V. 6, N. 12, Ed. 199, Art. 1332, 2012.

desses folículos durante o seu crescimento vão se degenerar no processo conhecido por atresia folicular, enquanto apenas uma minoria vai completar sua maturação e ovular (G. AISEN, 2008). Visando o melhor aproveitamento de fêmeas de qualidade genética superior a Transferência de Embriões surgiu como uma alternativa, baseando-se na superestimulação ovariana para o desenvolvimento de múltilpos folículos ovulatórios (Superovulação) e subseqüente fertilização e transferência destes embriões a receptoras, onde nas quais completarão seu desenvolvimento até o parto.

O sucesso dos programas de transferência de embriões depende, em grande parte, da resposta à superovulação, seu fator limitante (NEVES et al., 2005). Quanto a isso, recentes protocolos, que controlam a função folicular e luteínica, permitem iniciar o tratamento superovulatório em momento prédeterminado. O objetivo deste trabalho é revisar estes protocolos, a endocrinologia envolvida e os fatores que interferem no sucesso superovulatório.

\section{CICLO ESTRAL EM RUMINANTES}

O sistema nervoso central (SNC), por ação do hormônio liberador de gonadotrofinas $(\mathrm{GnRH})$, estimula na adeno-hipófise a síntese e secreção do hormônio luteinizante (LH) e hormônio folículo estimulante (FSH). Essas gonadotrofinas hipofisárias estimulam nas gônadas (ovário) a esteroidogênese ou síntese de esteróides gonadais (estrógeno e progesterona) e junto a estes participam do desenvolvimento dos folículos ovarianos e da ovulação (G. AISEN, 2008).

Em bovinos, a idade na época da puberdade de novilhas é influenciada por diversos fatores como a raça e o estado nutricional, mas geralmente está compreendida entre os 06 e 18 meses. O ciclo dura em média 21 dias. O proestro dura cerca de 3 dias, o estro em torno de 18 horas, o metaestro aproximadamente 3 a 4 dias e o diestro 10 a 13 dias. Possui padrões de 2 a 4 ondas foliculares, sendo mais comum a ocorrência de três ondas, sendo as 
FERNANDES NETO, V.P. et al. Técnicas de superovulação em ruminantes. PUBVET, Londrina, V. 6, N. 12, Ed. 199, Art. 1332, 2012.

duas primeiras, geralmente, anovulatórias. Em um ciclo natural, de cada onda de crescimento folicular, um único folículo "dominante" continua a crescer, enquanto suprime o crescimento dos folículos "subordinados". O período de ovulação é de 10 a 15 horas após o início do cio. Bovinos possuem ciclo poliéstrico contínuo. (HAFEZ \& HAFEZ, 2004 e GONÇALVES et al., 2001).

$\mathrm{Na}$ zona temperada, tanto ovinos como caprinos são estacionalmente poliéstricas, de modo que suas crias nascem durante a época mais favorável do ano - a primavera. Nas zonas tropicais, onde essa variação é menor, a tendência dos ovinos e caprinos é reproduzir-se durante o ano todo.

A puberdade, idade da primeira ovulação, ocorre de 5 a 7 meses em cabras e de 6 a 9 meses em ovelhas.

A duração normal do ciclo estral é de 17 dias para ovelhas e 21 dias para cabras, embora haja uma considerável variação devida a diferenças raciais, estágio da estação de monta e estresse ambientais em ambas as espécies. O estro dura de 24 a 36 horas na ovelha e de 24 a 48 horas na cabra. A raça, a idade, a estação, e a presença do macho influenciam na duração do cio.

A cabra e a ovelha apresentam ovulação espontânea. A ovelha ovula normalmente próximo ao fim do cio, cerca de 24 a 27 horas após o início. A maioria das raças caprinas ovula entre 24 a 36 horas após o início do cio (HAFEZ \& HAFEZ, 2004 e GONÇALVES et al., 2001).

\section{SUPEROVULAÇÃO EM RUMINANTES}

A superovulação pode ser definida como um método de estimular diversos folículos terciários desenvolverem até o estádio pré-ovulatório, com subseqüente ovulação (GONÇALVES et al., 2001). O hormônio folículo estimulante (FSH) tem função essencial no desenvolvimento do folículo. O uso de FSH exógeno para induzir superovulação é baseado nesta função fisiológica. Folículos em vários estágios de desenvolvimento estão normalmente presentes nos ovários, em qualquer tempo. Grupos consecutivos de folículos pequenos 
FERNANDES NETO, V.P. et al. Técnicas de superovulação em ruminantes. PUBVET, Londrina, V. 6, N. 12, Ed. 199, Art. 1332, 2012.

crescem, maturam e se degeneram ou ovulam. O FSH estimula o crescimento dos folículos pequenos, além de reverter a atresia em alguns casos. $O$ hormônio luteinizante (LH) estimula a produção de andrógenos na teça interna. Andrógenos tecais são usados como precursores para a produção de estrógenos pelas células granulosas que foram estimuladas pelo FSH (BÉNYEI \& BARROS, 2000). Injeções de FSH exógeno (eCG ou FSH) são amplamente utilizadas em programas de superovulação para aumentar o fornecimento de embriões de animais de qualidade genética. Aplicações subcutâneas ou intramusculares de eCG ou FSH estimulam o crescimento de folículos adicionais, os quais ovulam espontaneamente, sem a necessidade de LH ou hCG exógeno em vacas, búfalas, ovelhas e cabras (JAINUDEEN et al., 2004). O crescimento folicular pode ser sincronizado por diferentes drogas tal como progesterona, estradiol, uma combinação de progesterona e estradiol, e GnRH. O emprego de progesterona ou progestágenos em doses elevadas pode suprimir o suporte de LH para o folículo dominante, induzindo assim a sua atresia (THATCHER et al., 2001), dando possibilidade de início a uma nova onda folicular. A utilização do benzoato de estradiol em protocolos de superovulação tem a função de suprimir o desenvolvimento folicular, sendo mais eficiente quando combinado com P4. O GnRH ou LH tem sido muito utilizado para o controle da ovulação (pico de LH). A aplicação de um ou outro hormônio sincroniza a ovulação, permitindo que a inseminação seja realizada em tempo fixo. É imprescindível para a superovulação, dentro da TE, a utilização de uma agente luteolítico, como a prostaglandina F2a e seus análogos, o que também contribui para que haja inseminação em tempo fixo. A PGF2 a e seus análogos promovem a lise do corpo lúteo, o que proporciona o início de um novo ciclo estral.

O ponto de partida para a transferência de embriões é a sincronização do estro nas doadoras, realizando-se concomitantemente a indução de superovulação, utilizando-se de vários hormônios e seus análogos.

São inúmeros os protocolos para sincronização do estro e superovulação em ruminantes, os quais estão listados de acordo com a espécie: 
FERNANDES NETO, V.P. et al. Técnicas de superovulação em ruminantes. PUBVET, Londrina, V. 6, N. 12, Ed. 199, Art. 1332, 2012.

\section{a) Bovinos}

1. Duas injeções de PGF2 a (com 11 ou 12 dias de intervalo entre si). Após a segunda injeção, os animais podem ser cobertos/inseminados quando detectado o cio ou 72 e $96 \mathrm{~h}$ sem detecção de cio.

2. Progestágeno e PGF2 a. Um progestágeno (CIDR, PRID) é administrado como um pessário intravaginal por 7 dias com PGF2 a (injetado no sexto dia). As vacas são inseminadas com base no cio ou cerca de 84 horas após a administração de PGF2 a.

3. Progestágenos e estrógeno. Um estrógeno (5 $\mathrm{mg}$ de valerato de estradiol) e um progestágeno ( $3 \mathrm{mg}$ de Norgestomet) são injetados no primeiro dia de tratamento. O progestágeno é implantado por 9 dias, com início no dia 1. As vacas são inseminadas com base no cio (IADE) ou em um tempo fixo (IATF) após a remoção do implante.

4. Agonista de GnRH. Esse novo protocolo controla o desenvolvimento folicular e o tempo de vida do $\mathrm{CL}$. No dia 0, um agonista do $\mathrm{GnRH}$ (aGnRH) é injetado, no dia 6 a PGF2 a. Esse regime sincroniza os ciclos estrais de 70 a $80 \%$ de vacas cíclicas dentro de um intervalo de 4 dias, sem afetar a taxa de fertilidade (65 a 85\%). A precisão do cio e a alta taxa de fertilidade são devidas ao fato de o aGnRH luteinizar ou induzir a ovulação do folículo maduro e iniciar o recrutamento e a seleção de um novo folículo dominante. A injeção de PGF2 a causa regressão espontânea do corpo lúteo ou de um $\mathrm{CL}$ potencial induzido pelo $\mathrm{GnRH}$, ou ambos. Uma vantagem desse regime é que ele pode ser aplicado em qualquer estágio do ciclo estral e elimina o uso de progestágenos. Além disso, promove o reinício da atividade ovariana em vacas e novilhas acíclicas no pós-parto. Para IATF, um protocolo de aGnRH (D0), PGF2 a (D7) e GnRH (D8) e I.A. em momento prédeterminado pode ser adotado (HAFEZ \& HAFEZ, 2004). 
O tratamento superovulatório objetiva suprir a deficiência da concentração de FSH antes que o folículo dominante promova a redução da concentração endógena dessa gonadotrofina (GONÇALVES et al., 2001).

A superovulação é obtida através de injeções subcutâneas ou intramusculares de eCG ou FSH. Como o FSH tem uma meia-vida mais curta que o eCG, geralmente é necessário dividir a dose total e injetar com intervalos de 12 em 12 horas ao longo de 3 a 4 dias para estimular a mesma quantidade de crescimento folicular que resultaria de uma única injeção de eCG (HAFEZ \& HAFEZ, 2004).

No cio natural inicia-se o tratamento superovulatório entre o $8^{\circ}$ a $12^{\circ}$ dia após a manifestação do cio, coincidindo com o início da segunda onda folicular. Realiza-se 8 aplicações de FSH com intervalos de 12 em 12 horas, para aumentar o recrutamento de folículos. No terceiro dia da superovulação realiza-se 2 aplicações de prostaglandina com o intuito da luteólise do corpo lúteo, para que haja redução da progesterona e conseqüente pico de $\mathrm{LH}$, ocorrendo assim a ovulação (BÓ, 2002).

Atualmente os protocolos de eleição são os que se utilizam de indução do estro, com utilização de pessários ou implantes de progestágenos, benzoato de estradiol, PGF2a e seus análogos, FSH e GnRH/LH:

\section{PROTOCOLO 1}

\begin{tabular}{|c|c|c|c|c|c|c|c|}
\hline DIA & 0 & 4 & 5 & 6 & 7 & 8 & 9 \\
\hline Manhã & $\begin{array}{c}\mathrm{P} 4+\mathrm{E} 2 \\
\mathrm{P} 4(\mathrm{P} / \mathrm{I})^{*}\end{array}$ & FSH & FSH & $\mathrm{FSH}$ & $\begin{array}{c}\mathrm{FSH} \\
\mathrm{P} 4(\mathrm{P} / \mathrm{I})^{* *}\end{array}$ & $\mathrm{CIO}$ & IA \\
\hline Tarde & & FSH & FSH & $\mathrm{FSH}+\mathrm{PGF} 2 \mathrm{a}$ & $\mathrm{FSH}$ & IA & \\
\hline
\end{tabular}




\section{PROTOCOLO 2}

\begin{tabular}{|c|c|c|c|c|c|c|c|}
\hline DIA & 0 & 4 & 5 & 6 & 7 & 8 & 9 \\
\hline Manhã & $\begin{array}{c}\mathrm{P} 4+\mathrm{E} 2 \\
\mathrm{P} 4(\mathrm{P} / \mathrm{I})^{*}\end{array}$ & FSH & FSH & FSH & $\begin{array}{c}\mathrm{FSH} \\
\mathrm{P} 4(\mathrm{P} / \mathrm{I})^{* *}\end{array}$ & $\mathrm{LH}$ & IA \\
\hline Tarde & & FSH & FSH & $\mathrm{FSH}+\mathrm{PGF} 2 \mathrm{a}$ & $\mathrm{FSH}$ & IA & \\
\hline
\end{tabular}

\section{PROTOCOLO 3}

\begin{tabular}{|c|c|c|c|c|c|c|c|}
\hline DIA & 0 & 4 & 5 & 6 & 7 & 8 & 9 \\
\hline Manhã & $\begin{array}{c}\mathrm{P} 4+\mathrm{E} 2 \\
\mathrm{P} 4(\mathrm{P} / \mathrm{I})^{*}\end{array}$ & FSH & $\mathrm{FSH}$ & FSH & $\begin{array}{c}\mathrm{FSH} \\
\mathrm{P} 4(\mathrm{P} / \mathrm{I})^{* *}\end{array}$ & IA & IA \\
\hline Tarde & & FSH & $\mathrm{FSH}$ & $\mathrm{FSH}+\mathrm{PGF} 2 \mathrm{a}$ & $\mathrm{FSH}$ & $\begin{array}{c}\text { IA } \\
\text { GnRH }\end{array}$ & \\
\hline
\end{tabular}

Segundo Andrade et al. (2002), as fêmeas doadoras podem ser sucessivamente superovuladas com protocolos que envolvam dispositivos intravaginais ou implantes auriculares para a sincronização do estro, o importante é que o intervalo entre duas superovulações consecutivas deve ser de, no mínimo, cinco semanas.

\section{b) Caprinos e Ovinos}

O protocolo convencional em caprinos e ovinos encontra-se na tabela a seguir. 
FERNANDES NETO, V.P. et al. Técnicas de superovulação em ruminantes. PUBVET, Londrina, V. 6, N. 12, Ed. 199, Art. 1332, 2012.

Tabela 1.0 - Protocolo convencional de superovulação em caprinos e ovinos

\begin{tabular}{|c|c|}
\hline Cabra & Ovelha \\
\hline D0 $=$ colocar esponja & D0 $=$ colocar esponja \\
\hline D8 $=$ manhã: $1^{\mathrm{a}}$ aplic. FSH+ & D12 = manhã: $1^{\text {a }}$ aplic. FSH \\
\hline \multicolumn{2}{|l|}{ Prostaglandina } \\
\hline tarde: $2^{\mathrm{a}}$ aplicação FSH & tarde: $2^{\mathrm{a}}$ aplicação FSH \\
\hline D9= manhã: $3^{a}$ aplicação FSH & D13 = manhã: $3^{a}$ aplicação FSH \\
\hline tarde: $4^{\mathrm{a}}$ aplicação FSH & tarde: $4^{\mathrm{a}}$ aplicação FSH \\
\hline $\mathbf{D 1 0}=$ manhã: retirar esponja $+4^{a}$ & $\mathbf{D 1 4}=$ manhã : retirar esponja $+4^{a}$ \\
\hline aplic. FSH & aplic. FSH \\
\hline tarde: $6^{a}$ aplicação FSH & tarde: 6a aplicação FSH \\
\hline D11 = Obs. Cio $+\mathrm{IA} /$ monta natural & D15 = Obs. Cio $+\mathrm{IA} /$ monta natural \\
\hline D12 $=$ Obs. Cio $+\mathrm{IA} /$ monta natural & $\mathbf{D 1 6}=$ Obs. $\mathrm{Cio}+\mathrm{IA} /$ monta natural \\
\hline
\end{tabular}

Adaptada de G. AISEN, 2008.

A sincronização do estro com análogos sintéticos da progesterona data da década de 60 (ROBINSON, 1967) e, desde então, pessários vaginais, como esponjas vaginais de poliuretano, foram adotadas como o veículo responsável pelo "priming" de progesterona que precederia o tratamento hormonal de indução e/ou sincronização do estro de pequenos ruminantes. Essas são impregnadas de $45 \mathrm{mG}$ de Acetato de Fluorogestona - FGA (Intervet e CEVA França) ou 60 mG de Medroxiprogesterona - MAP (Syntex, Argentina) e de uso único. Produzido em matriz de silicone e impregnado com $300 \mathrm{mG}$ de progesterona natural, o CIDR (Carter Holt Harvey, Nova Zelândia) é igualmente utilizado, tendo como vantagem a possibilidade de reutilização, quando adequadamente estocado (FREITAS et al., 1997; GUIDO et al., 1999; MOTLOMELO et al., 2002).

A promoção da superovulação se dá pelo uso de FSH (tabela 2) em doses decrescentes, mas pode-se utilizar também ECG. Para a sincronização do estro pode-se utilizar o cloprostenol (análogo da PGF2a) na dosagem de $100 \mu \mathrm{g}$ no 
FERNANDES NETO, V.P. et al. Técnicas de superovulação em ruminantes. PUBVET, Londrina, V. 6, N. 12, Ed. 199, Art. 1332, 2012.

9a dia, em protocolos de 11dias com esponjas impregnadas com progestágenos (BARIL et al., 1988).

Tabela 2.0 - Doses das marcas comerciais de FSH mais comuns

\begin{tabular}{ll}
\hline Produto & Doses caprina/ovina \\
\hline Folltropin-V & $130 \mathrm{mg}$ \\
Pluset & $250 \mathrm{UI}$ \\
FSH-P Schering & $16 \mathrm{mg}$
\end{tabular}

Adaptada de G. AISEN, 2008.

FATORES QUE INTERFEREM NA RESPOSTA SUPEROVULATÓRIA

São vários os fatores que interferem na resposta superovulatórioa tais como regressão lútea precoce, relação LH/FSH, tipo de fármaco utilizado, imunidade, escore corporal e nutrição, dentre outros.

\section{Regressão lútea precoce}

A regressão lútea precoce, também ocorre na ovelha. O fenômeno parece estar associado a elevadas concentrações plasmáticas de estrógenos durante a fase lútea inicial e, em conseqüência, nota-se um decréscimo na taxa de recuperação de embriões. Em ovelhas superovuladas, a regressão lútea precoce pode variar de $6,0 \%$ a 75,0\% (FUKUI et al., 1998; LOPES Jr et al., 2006).

A regressão prematura de corpo lúteo parece estar ligada à ação da cicloxigenase e posterior atividade de prostaglandina sobre o corpo lúteo, como sugerido por Battye et al.(1988) e Gilbert et al. (1990). Dentre as drogas antiinflamatórias não-esteróides (DAINES), o flunixin meglumine é o mais potente inibidor da cicloxigenase, enzima responsável pela transformação do ácido araquidônico em prostaglandinas (ANDRADE \& MADER, 1998), mais especificamente em seu principal precursor, o 13,14-dihidro- 
FERNANDES NETO, V.P. et al. Técnicas de superovulação em ruminantes. PUBVET, Londrina, V. 6, N. 12, Ed. 199, Art. 1332, 2012.

15cetoprostaglandina $F_{2 a}$. Lopes $\mathrm{Jr}$ et al. (2004) trabalhando com cabras Saanen e Anglo-nubiana, realizando 8 aplicações de flunixin-meglumine com intervalos de $12-12 \mathrm{~h}$ na dosagem de $1,1 \mathrm{mg} / \mathrm{kg}$ comprovou a eficiência deste antiinflamatório não-esteroidal em evitar a regressão prematura do CL. O flunixin-melgumine também pode ser eficiente com a mesma dose $(1,1 \mathrm{mg} / \mathrm{kg})$ sendo aplicado aplicado apenas uma vez ao dia, diminuindo assim os custos com este tratamento (SALLES et al., 1998).

\section{Relação $L H / F S H$}

Em relação às concentrações do hormônio folículo estimulante (FSH) e do hormônio luteinizante (LH) presentes no extrato pituitário comumente utilizado para estimular a resposta ovulatória, Visintin et al. (1999) encontraram melhores resultados em preparações com baixa concentração de LH, salientando que as altas concentrações de LH causam ovulação prematura ou luteinização de folículos, ocasionando baixa resposta superovulatória.

\section{Tipo de fármaco}

Comparando o eCG com FSHp (FSH de origem suína) na superovulação de cabras e ovelhas, Armstrong \& Evans (1983) obtiveram uma maior taxa de ovulação, uma menor incidência de falha na ovulação e uma maior média de embriões colhidos por fêmea com o uso de FSHp em detrimento do uso de eCG.

\section{Imunidade}

Uma diminuição na resposta ovariana foi observada em cabras submetidas a tratamentos repetidos com FSHp, devido a presença de anticorpos anti-FSHp (BARIL et al., 1990). O Ecg também induz uma resposta imunológica, com produção de anticorpos anti-eCG, o que determina para tratamentos superovulatórios subseqüentes, um aumento na dose para que se obtenha o mesmo efeito. 
FERNANDES NETO, V.P. et al. Técnicas de superovulação em ruminantes. PUBVET, Londrina, V. 6, N. 12, Ed. 199, Art. 1332, 2012.

Em 1977, Bindon \& Piper, utilizaram um soro anti-eCG para eliminar os efeitos deste hormônio. O momento mais apropriado para administrar este soro é logo após o pico préovulatório de LH. Na prática, é administrado no momento da $1^{\text {a }}$ inseminação artificial. Em geral o soro anti-eCG melhora os resultados da superovulação, mesmo que existam registros de trabalhos, nos quais o soro não exerceu nenhum efeito benéfico (CHUPIN et al., 1988).

\section{Escore corporal e nutrição}

A alimentação exerce influência sobre a reprodução e os nutrientes apresentam mecanismos específicos de atuação sobre a eficiência reprodutiva. Os níveis nutricionais podem afetar o desenvolvimento e a função dos órgãos reprodutivos, além de acarretar alterações do funcionamento do sistema endócrino envolvido com a reprodução (MAGGIONI, D. et al., 2008).Salles (2001) estudou a relação entre a condição corporal de matrizes da raça Santa Inês, avaliadas com escore de 1 a 5 , e a resposta ao tratamento superovulatório. O número médio de corpos lúteos foram 9,$0 ; 7,8 ; 7 ; 7$ e 7,3 para ovelhas em condição corporal igual a 2, 3, 4 e 5 respectivamente. Foi observada uma correlação negativa entre a condição corporal e o número de corpos lúteos, mostrando que as ovelhas gordas apresentam menor resposta superovulatória e que seria interessante se trabalhar com animais em condição corporal igual a 2 .

Tanto bovinos como caprinos e ovinos que recebem flushing antes do tratamento superovulatório apresentam melhor resposta ao tratamento.

Um dos efeitos da nutrição sobre o desenvolvimento do oócito é o estresse celular, expresso através da aceleração do metabolismo embrionário, o que pode comprometer a sobrevivência do embrião no período de préimplantação (LEESE, 2002). Esse efeito adverso sobre os oócitos provavelmente envolve a inibição no crescimento e metabolismo das células da granulosa que sustentam o oócito (ROOKE et al., 2004). Outros fatores importantes parecem ser a fase e o tamanho específico do folículo, onde, folículos pré-antrais e de tamanho médio são os mais afetados. Sabendo-se 
FERNANDES NETO, V.P. et al. Técnicas de superovulação em ruminantes. PUBVET, Londrina, V. 6, N. 12, Ed. 199, Art. 1332, 2012.

que folículos de tamanho médio podem ter sua ovulação induzida através do uso de gonadotrofinas, os efeitos adversos da nutrição parecem ser mais prevalentes em animais estimulados por gonadotrofinas que naqueles que ovulam espontaneamente.

A infusão de insulina em novilhas aumentou tanto o diâmetro do folículo dominante (SIMPSON et al., 1994) quanto a taxa de ovulação em animais com restrição energética (HARRISON \& RANDEL, 1986).

\section{CONSIDERAÇÕES FINAIS}

Nas últimas quatro décadas houve um bom avanço nas técnicas de superovulação, o que pode ajudar na difusão e utilização da TE. Contudo o uso da transferência de embriões, sobretudo da superovulação, ainda não ocorre em grande escala em nosso país devido a vários fatores dentre os quais se destacam o alto custo e o baixo rendimento geral. Com isso há uma grande necessidade de desenvolvimento de protocolos mais simples, eficientes, menos estressantes, menos onerosos e que garantam taxas de recuperação elevadas e constantes, e que sejam adaptados ao nosso ambiente e sistema de produção de ruminantes.

\section{REFERÊNCIAS BIBLIOGRÁFICAS}

ANDRADE, J. C. O.; OLIVEIRA, M. A. L.; LIMA, P. F. Use steroid hormone treatments prior to superovulation in Nelore donors. Animal Reproduction Science, Amsterdam, v.69, n.1-2, p.9-14, 2002.

ANDRADE, S. F.; MADER, R. C. D. Uso de droga antiinflamatória não esteróide no tratamento do choque endotóxico em cães. Vet News, v. 5, n.34, p. 8-10, jul/ago. 1998.

ARMSTRONG, D. T. \& EVANS, G. Factors influencing sucess of embryo transfer in sheep and goats. Theriogenology, 19: 31-42, 1983.

BARIL, G. et. al. Are decreased superovulatory responses in goats related to porcine follicle stimulating hormone antibodies? In: Reunion Association Européene de Transfert Embryonnaire, 6, Lyon, p. 122, 1990. 
BARIL, G.; CASAMITJANA, P.; VALLET, J. C. Embryo production, freezing and transfer in Angora, Alpine and Saanen goats. In: $4^{\circ}$ Colloque Scientifique de Association Européene de Transfert Embryonnaire, Lyon, 9-10, France, p. 67-93, september 1988.

BATTYE, K. M.; FAIRCLOUGH, R. J.; CAMERON, A. W. N.; TROUNSON, A. O. Evidence for prostaglandin involvement in early luteal regression of the superovulated nanny goat (Capra hircus). Journal of Reproduction and Fertility, v. 84, n. 2, p. 425-430, nov. 1988.

BENYEI, B.; BARROS, C. C. W. Effect of superovulation on preformance of bovine embryo donors imported from temperate zone to tropical climate during the first two years of adaptation. Arq. Bras. Med. Zootec., Vol. 52, no 4, p. 366-371, aug, 2000.

BINDON, B.; PIPER, L. Induction of ovulation in sheep and cattle by injection of PMSG and ovine anti-PMSG immune serum. Theriogenology. v. 4, p. 171, 1977.

BÓ, G. A. Sincronizacion Del desarollo folicular y luteal in grupos donantes y receptoras de embriones bovinos. In: II Curso de abordagem teórico-prática de novas técnicas de sincronização sem observação de cio em bovinos (IA e TE). Cornélio Procópio-PR. Anais, 2002.

CHUPIN, D.; STEINER, M.; SAUMANDE, J. Neutra-PMSG injected early after the LH peak dose not improve ovulation rate in PMSG treated heifers. Proceedings XI international Congress of Animal Reprodution and Artificial Insemination, Dublin, Ireland. p. 147, 1988.

FREITAS, V. J. F.; BARIL, G.; SAUMANDE, J. Estrus synchronization in dairy goats: use of flurogestone acetate vaginal sponges or norgestomet ear implants. Anim Reprod Sci, V.46, p.237-244, 1997.

FUKUI, Y.; OKADA, M.; ISHIDA, M. Incidence of premature luteal regression in ewes superovulated with a single injection of follicle-stimulating hormone combined with equine chorionic gonadotropin. J Reprod Dev, v.44, p.407-412, 1998.

G. AISEN, E. Reprodução Ovina e Caprina. 1 ed. São Paulo: MedVet, 2008. 203p.

GILBERT, D. E.; COONROD, S. A.; WRITING, C. J.; PASHEN, R. L. Comparison of a progesterone intravaginal device $\left(\mathrm{CIDR}^{\mathrm{tm}}\right.$ ) with flunixine meglumine (finadine ${ }^{\mathrm{tm}}$ ) for reducing the effects of corpora lutea regression in the goat. Theriogenology. v.33, p. 230, 1990.

GONÇALVES, P. B. D. et. al. Biotécnicas aplicadas à reprodução animal. São Paulo: Livraria Varela, 2001.

Guido, S. I.; OliveirA, M. A. L.; LIMA, P. F.; PAES BARRETO, M. B. D.; ARAÚJO, E. P. M. Reutilização do controlled internal drug release (CIDR) e do programa syncro-mate-B (SMB) para sincronizar o estro de cabras Saanen. Rev Bras Repr An, v. 23, n. 3, p. 367-69, 1999.

HAFEZ, B. \& HAFEZ, E. S. E. Reprodução Animal. 7 ed. São Paulo: Manole, 2004. 513p.

HARRISON, L.M.; RANDEL, R.D. Influence of insulin and energy intake on ovulation rate, luteinizing hormone and progesterone in beef heifers. Journal of Animal Science v.63, p.1228-1235, 1986.

JAINUDEEN, M. R.; WAHID, H.; HAFEZ, E. S. E. Indução da ovulação, produção e transferência de embriões. In: HAFEZ, E. S. E. \& HAFEZ, B. REPRODUÇÃo ANIMAL, 7a ed. Barueri, Ed. Manole, 2004. p.413-419.

LEESE, H.J. Quiet please, do not disturb: a hypothesis of embryo metabolism and viability. Bioessays v.24, p.845-849, 2002. 
LOPES JR, E. S. Uso do flunixin meglumine na prevenção da regressão lútea premature em cabras submetidas a tratamento superovulatório. Vet News, ano XI, n. 68, 2004.

LOPES JR, E. S.; MAIA, E. L. M. M.; ALMEIDA, K. C.; PAULA, N. R. O.; TEIXEIRA, D. I. A.; RONDINA, D.; SELAIVE-VILLAROEL, A. B.; FREITAS, V. J. F. Influência dos níveis plasmáticos de progesterona sobre a resposta ovariana e produção embrionária de ovelhas Morada Nova (variedade branca). Acta Vet Sci, v.34, p.510, 2006. Resumo.

MAGGIONI, D.; ROTTA, P. P.; ZAWADZKI, F.; MARQUES, J.; PRADO, R. M.; PRADO, I. N. Influência da proteína sobre a reprodução animal: uma revisão. Campo Digital, v. 1, n. 2, p. 105-110, jan-out, 2008.

MOTLOMELO, K. C.; GREYLING, J. P. C.; SCHWALBACH, L. M. J. Synchronization of oestrus in goats: the use of different progestagen treatments. Small Rum Res, v.45, p.45-49, 2002.

NEVES, E.F.; RAMOS, A.F.; MARQUES JUNIOR, A.P. Pré-tratamento com somatotropina bovina (rbST) na superovulação de doadoras da raça Holandesa. Arq. Bras. Med. Vet. Zootec., v.57, p.205-209, 2005.

ROBINSON, T. J. The control of ovarian cycle in the sheep. Sydney: Sydney University Press, 1967. 258 p.

ROOKE, J.A.; EWEN, M.; MACKIE, K.; STAINES, M.E.; MCEVOY, T.G.; SINCLAIR, K.D. Effect of ammonium chloride on the growth and metabolism of bovine ovarian granulosa cells and the development of ovine oocytes matured in the presence of bovine granulosa cells previously exposed to ammonium chloride. Animal Reproduction Science v.84, p.53-71, 2004.

SALLES, H. O. condição corporal e resposta superovulatória em ovelhas da raça Santa Inês. In: $3^{\circ}$ Simpósio de recursos genéticos para a Américan, Londrina, p. 471, 2001.

SALLES, H. O. et. al. Diferentes posologias de flunixin meglumine na prevenção da regressão premature de corpos lúteos em cabras superovuladas. Ciência Animal, 8 (2): 69-74, 1998.

SIMPSON, R.B.; CHASE JR., C.C.; SPICER, L.J.; VERNAN, R.K.; HAMMOND, A.L.; RAE, D.O. Effects of exogenous insulin on plasma and follicular insulin like growth factor I, insulin like growth factor binding activity, follicular oestradiol and progesterone and follicular growth in superovulated Angus and Brahman cows. Journal of Reproduction and Fertility, V.102, p.483-492, 1994.

THACHER, W. W. et. al. Effects of hormonal treatments on reproductive performance and embryo production. Theriogenology. v. 55, n. 1, p. 75-89, 2001.

VISINTIN, J. A. et. al. Superovulação de novilhas da raça Nelore com diferentes doses de FSH/LH e congelação de embriões pelo método one-step com etilenoglicol. Braz. J. Vet. Res.

Anm. Sci, vol. 36, n. 5, 1999. 